\title{
SEISMIC DESIGN ISSUES
}

\author{
Lajos György KOPENETZ, ${ }^{1}$ Alíz Éva MÁTHÉ,, ${ }^{2}$ Ferdinánd-Zsongor GOBESZ ${ }^{3}$ \\ Technical University of Cluj-Napoca, Department of Structural Mechanics, Cluj-Napoca, Romania \\ ${ }^{1}$ ludovic.kopenetz@mecon.utcluj.ro \\ ${ }^{2}$ aliz.mathe@mecon.utcluj.ro \\ ${ }^{3}$ go@mecon.utcluj.ro
}

\begin{abstract}
Earthquake zones cover a significant part of our earth, therefore, when planning and designing residential areas, factories, or other human establishments, professionals have to take into account the seismic hazard of that area. The current earthquake standard in Romania is based on the European code. This paper presents, beside the most significant structural composition rules, the applicable methods that can be used to ensure sufficient load bearing requirements.
\end{abstract}

Keywords: earthquake, seismic load, bearing structure.

\section{Introduction}

Earthquakes are one of the most devastating natural disasters, a major threat to the integrity of buildings and people. The rate of destruction can also be increased by the resulting fires caused by broken gas pipes and snapped electrical wires, and if the water mains are damaged, the efficient extinguishing of fires becomes impossible.

Since most of the earth's mainland is in an earthquake zone and human settlements are becoming more widespread, professionals are also having to take into account the degree of seismic hazard in the area in which they are located and designed. In order to be able to take into account the seismic hazard during the design and building phases of structures, they need to be aware of the impact of the possible earthquakes and of all its characteristics.

\section{Earthquake}

It is known that our Earth is made up of several layers (crust, top and lower mantle, and outer and inner core), earthquakes occur in the earth's crust which is about 60 kilometres thick. As a result of the constant movement of our Earth, both surface and underground forces create tensions that manifest themselves in the form of elevation, sinking, and wrinkling of the surface. An earthquake is cau- sed by the sudden release of tension or accumulated energy. The most common cause of energy release is the breaking of the solid crust (so-called tectonic fracture). The formation of tectonic earthquakes (due to the accumulation of tensions) is preceded by slow deformation in rocks. If the elastic tensions - which will gradually grow with the increase of the deformation - exceed the strength of the rock, some of the potential energy of the elastic deformation will suddenly become kinetic energy, thus an earthquake will occur.

Aside from tectonic quakes, there may occur other trembles associated with the activity of volcanoes (less frequent and local), landslides or collapse tremors (usually karst phenomena), artificial quakes (due to man-made above ground or underground explosions).

At the moment of the earthquake, a rupture zone is formed in the rocks. The part where steady deformation occurs is called the focus (hypocentre). The perpendicular projection of this to the surface of the earth is the epicentre of the earthquake, the surface movement being the most intense in this area. The liberated energy of motion extends beyond the small area of the hypocentre in the form of elastic waves, spreading in the solid crust as longitudinal and transvers waves. The Love-Rayleigh surface waves originate from the epicentre. These are combinations of the above types 
and completely irregular due to different physical phenomena (interference, reflection, inhomogeneity of soil layers). In fact, these are the waves that pose a direct threat to the above-ground structures.

As opposed to the older attempts to view surface movement in terms of mathematical formulas, the current position is that surface movements should be regarded as irregular impulses that follow each other at atypical intervals (this kind of effect is called transient phenomenon). This implies a noteworthy statement for buildings: the structures affected by the waves do not make compulsive vibrations, but disturbed oscillation at irregular intervals. Unlike the case of periodic effects, resonance and fatigue has a very little likelihood of appearing.

There are two ways to measure earthquakes. Engineering seismology uses earthquake strength scales, while geophysicists measure the energy released in the quake nest. The development of earthquake strength scales took place towards the end of the 18 th century and in the $19^{\text {th }}$ century. All earthquake strength scales use generic descriptive signs created by the quake. The most important of these is the degree of damage to buildings and the permanent phenomena created on the ground. Currently, engineering seismology uses the MSC-64 (Mercalli-Sieberg-Cancani) scale to determine the strength of a quake. [1].

The MSC-64 scale, which interprets the strength of the quake based on the changes caused by surface movements and accelerations, consists of 12 degrees. Weaker than VI degree quakes do not pose a threat to expertly designed and properly constructed buildings. There is no realistic possibility of protection against higher than IX degree ruptures, given current building materials and structural systems, as horizontal accelerations are too large (the 1963 Skopje earthquake in the inner city area was VIII-IX degree in intensity. [2]).

Geophysicists primarily use the Richter scale, which instead of showing the strength is related to the energy: it shows how much energy is released in the nest of the quake, which indirectly determines the size or magnitude of the quake [1]. The magnitude and the earthquake energy are logarithmically related to each other. According to the Richter scale, an earthquake maximum of 8.9 can occur, because the solid crust cannot accumulate more energy without breaking.

\section{Design issues}

There was a time when many architects did not take this natural phenomenon seriously and considered protection against earthquakes a futile expense. Such positions have been refuted by the natural disasters that have taken place in the meantime. The costs of protection would have been significantly lower than initially thought (the excess expenditure would not exceed 7 percent). The easiest protection against weaker earthquakes is good structural design and execution, which would mean no extra cost; on the contrary, it can save money.

Although earthquake movements are multi-directional, during conventional structural design only horizontal forces are usually taken into account [3].

According to previous research, in case of earthquakes, those building structures whose dynamic and mass characteristics were picked (by proper location and structural design) in such way that the resulting seismic forces would be as small as possible, (and not those built by oversizing the otherwise poorly designed structure), are behaving satisfactorily [4]. Seismic forces have to be perceived as a dynamic effect and the resulting load should be determined by the methods of dynamics, i.e. it is not enough to increase the static loads with safety factors. The subsoil conditions are of great importance during design, as the characteristics of surface waves depend primarily on these. In rigid, solid soils, the friction losses are significantly higher than in loose soils. Also, the inherent vibration frequency of the soils is different, in the case of solid soils it is significantly higher than in case of loose soils. Thus, rigid structures with high vibration frequency are in a more favourable position on loose soils, than flexible structures with low inherent frequency on solid soils.

There are several methods for calculating seismic forces. Given the complexity of the calculations, the use of computers and the introduction of model experiments are of great importance.

The most important "composition" rules are:

- The floor plan of the building should be close to a square (ideally to a circle) and out-stretched wings or building parts are undesirable.

-It should be unconditionally symmetrical, preferably in both directions. The centre of gravity of the building should match the centre of gravity of the stiffening elements. 
- The stiffening walls and elements should be as uniform as possible. The two-way rigidity of the ground floor is very important. In the 1974 earthquake in Bucharest, almost without exception, those downtown buildings where the ground floor was replaced by shops and the required additional stiffening was missing, collapsed. It is also important to use top rim.

- The weight of the structure must be lightened, avoiding weak joints and elements.

Great care should be taken when considering the proportions of rigidity. This issue is highly important in the case of earthquakes. As an analogue, if one of the four springs of a car's suspension is replaced with a 3 times weaker one, it will immediately show in the way the car performs...

Compared to other structural solutions, steel construction is the most resistant to earthquakes (in addition to the correct construction process), although steel structures are very weak against fire.

Even in such a huge earthquake as the 1923 Tokyo (8.3 on the Richter scale), steel structures suffered relatively little damage [5]. The safety of the structure is enhanced by the flexibility of the structure, which provides greater energy absorption compared to other structures. Experience has shown that steel structures can bear ten times more deformation than a reinforced concrete structure. For both reinforced concrete and steel structures, the uniform rigidity of the building is favourable because, for example, flexible slabs can suffer large distortions due to differential deformation. That is why designers are choosing columns (and beams) with equal rigidity at the same level, and change them only gradually, from floor to floor. Among the reinforced concrete structures, those built with monolithic technology proved to be the most resistant. For large-panel reinforced concrete structures, the solutions with fewer gaps and with more secure panel joints are more advantageous against trembles.

So far, the results suggest that even against the worst earthquakes there is a realistic chance of protection.

\section{Earthquake-related calculation issues}

The current earthquake protection code in Romania [6] relies on the European EC8 (EN 1998-1) earthquake standard, but exceeds it. While the EC8 takes a 150-year average return interval for the size of the earthquake, the $\mathrm{P} 100-1$ requires
225 years (greater earthquakes may occur over a longer period). Another important difference is that while the EC8 has two classes of ductility (high and medium), in P100-1 a third was introduced (low). These standards contain strict requirements:

- performance requirements;

- compliance criteria;

-no-collapse requirement;

- damage limitation requirements.

- The following methods may be used by the structural designer to provide the required load-bearing capacity:

- the lateral force method (replacing horizontal dynamic forces acting on the building with equivalent static forces);

-response spectrum analysis (modal response spectrum analysis);

- nonlinear static or push over analysis;

- non-linear dynamic or time-history analysis;

- probabilistic method.

Currently, the first two methods are used more often in structural design.

The effect of earthquakes on a building is actually an inertial force $(F)$, given by the product between the $(m)$ mass of the building and the $(a)$ acceleration of the induced motion on the structure (Newton's Law - 1687):

$$
F=-m \cdot a
$$

Thus, it is obvious that structural acceleration is a function of the $\left(a_{g}\right)$ maximum horizontal ground acceleration induced by the earthquake. The $a_{g}$ is the product of the relative acceleration $\left(k_{s}\right)$ and the gravitational acceleration:

$$
a_{g}=k_{s} \cdot g
$$

The elastic response spectrum of absolute accelerations for horizontal ground movement (measured in $\mathrm{m} / \mathrm{s}^{2}$ ) can be determined as follows:

$$
S_{e}(T)=a_{g} \cdot \beta(T)
$$

The acceleration of the structure is obtained from the acceleration of the ground, based on the response spectra. Response spectrum curves depend on:

-the soil class, i.e. on the own period of the ground movement $\left(T_{c}\right.$ ) (Figure 1. and Table 1.); - the dynamic properties of the structure (rigidity, mass distribution, periods of own vibration, structural damping factors).

The values of the $\beta(T)$ elastic response spectrum of the normalized horizontal ground acceleration, considering the $\xi=0.05$ conventional value of the critical attenuation, are given by the following formulas as a function of the $\left(T_{B}, T_{C}, T_{\mathrm{D}}\right)$ control periods: 


$$
\begin{array}{ll}
T_{C} \leq T_{B} & \beta(T)=1+\frac{\left(\beta_{0}-1\right)}{T_{B}} \cdot T \\
T_{B}<T \leq T_{C} & \beta(T)=\beta_{0} \\
T_{C}<T \leq T_{D} & \beta(T)=\beta_{0} \cdot \frac{T_{C}}{T} \\
T>T_{D} & \beta(T)=\beta_{0} \cdot \frac{T_{C} \cdot T_{D}}{T^{2}}
\end{array}
$$

In the above formulas, $T$ is the oscillation period of a flexible structure with one degree of dynamic freedom, while $\beta_{0}$ is the dynamic increase coefficient of the horizontal ground acceleration $\left(\beta_{0}=2.5\right)$. The $T_{c}$ corner period represents the boundary between the spectra of absolute accelerations and relative velocities and is measured in seconds. $T_{B}$ can be calculated in a simplified manner $\left(T_{B}=0.2 \cdot T_{C}\right)$, while $T_{D}$ represents the boundary between the spectra of the maximum relative velocities and the relative displacements.

Since the structure should work in the elastic-plastic range during the design and dimensioning, the normalized response spectrum for design is obtained by introducing the $q$ behavioural factor. Thus, the structural acceleration spectrum for design can be described by the following functions:

$$
\begin{aligned}
& 0<T \leq T_{B} \quad S_{d}(T)=a_{g} \cdot\left\lceil 1+\frac{\frac{\beta_{0}}{q}-1}{T_{B}} \cdot T\right\rceil \\
& T>T_{B} \quad S_{d}(T)=a_{g} \cdot \frac{\beta(T)}{q}
\end{aligned}
$$

The lateral force method can be used as an approximation if the vibration times are well separated (i.e., non-coupled vibrations) and the base period is $T<1.6 \mathrm{~s}$.

The bottom shear force is given by the formula: $F_{b}=\gamma_{I} \cdot S_{d}\left(T_{1}\right) \cdot m \cdot \lambda$

where $S_{d}\left(T_{1}\right)$ is the structural acceleration spectrum for design corresponding to the fundamental period (for the first vibration mode) $\left[\mathrm{m} / \mathrm{s}^{2}\right] ; T_{1}$ is the fundamental period [s]; $\gamma_{I}$ is the importance class of the building $\left(\gamma_{I}=0,8 \ldots 1,4\right) ; m$ is the mass of the building; and $\lambda$ is a modifying factor (if $T_{1}$ $<T_{C}$ and if the building has more than two levels then it's value is 0.85 ; otherwise 1.0 ).

The fundamental period can be estimated by several methods, for example:

$$
T_{1}=C_{t} \cdot H^{3 / 4}
$$

where $H$ is the height of the building (from the ground) [m], while $C_{t}$ is 0.085 for steel structures; 0.075 for reinforced concrete or centrally stiffened steel structures; and 0.050 in other cases.

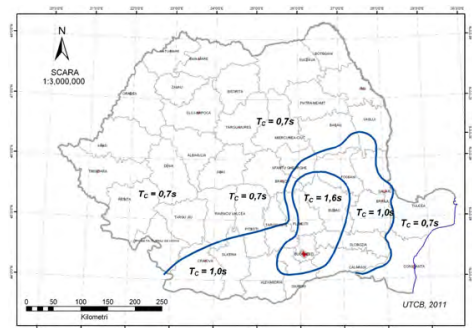

Figure 1. Territorialisation of Romania according to the $T_{C}$ control period [6].

Table 1. The values of the $T_{B}, T_{C}$ and $T_{D}$ control periods for horizontal ground movement [6]

\begin{tabular}{|l|l|l|l|}
\hline $\boldsymbol{T}_{\boldsymbol{C}}$ & $0,70 \mathrm{~s}$ & $1,00 \mathrm{~s}$ & $1,60 \mathrm{~s}$ \\
\hline $\boldsymbol{T}_{\boldsymbol{B}}$ & $0,14 \mathrm{~s}$ & $0,20 \mathrm{~s}$ & $0,32 \mathrm{~s}$ \\
\hline $\boldsymbol{T}_{\boldsymbol{D}}$ & $3,00 \mathrm{~s}$ & $3,00 \mathrm{~s}$ & $2,00 \mathrm{~s}$ \\
\hline
\end{tabular}

\section{Conclusions}

Today's structural design of buildings is unthinkable without consideration of earthquake protection. The development of standards is moving towards increasing safety. A more detailed nonlinear study can be time consuming and costly for complex large structures and requires complex computing equipment. If the structural engineer is aware of the phenomenon of the earthquake and of its impact on the building, adequate safety can be achieved even with simplified procedures and fitted structural shaping.

\section{References}

[1] Musson R. M. W., Grünthal G., Stucchi M.: The comparison of macroseismic intensityscales. Journal of Seismology, Springer Verlag, 14/2. (2009) 413-428.

[2] Suhadolc P., Sandron D., Fitzko F., Costa G.,: Seismic ground motion estimates for the M6.1 earthquake of July 26, 1963 at Skopje, Republic of Macedonia, Acta Geodaetica et Geophysica Hungarica, 39/2-3. spec. iss. (2004) 319-326,

https://doi.org/10.1556/AGeod.39.2004.2-3.13

[3] Kopenetz L. Gy.: Gondolatok statikusoknak. Kriterion Könyvkiadó, Kolozsvár, 2006.

[4] Kegyes-Brassay O., Ray R. P.: Earthquake Risk Assessment - Effect of a Seismic Event in a Moderate Seismic Area, Acta Technica Jaurensis, 9/1. (2016) 1-15.

[5] de Boer J. Z., Sanders D. Th.: Earthquakes in human history: the far-reaching effects of seismic disruptions., Princeton University Press, Princeton, New Jersey, 2005, 278.

[6] P100-1: Cod de proiectare seismică. Partea I - prevederi de proiectare pentru cladiri, MDRAP, 2013. 